\title{
Comparison of Success of Buccal Infiltration Versus Intraligamentary Local Anesthetic Techniques in Mandibular First Molar with Irreversible Pulpitis
}

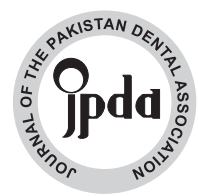

\author{
Muhammad Haris Naeem ${ }^{1}$ \\ BDS \\ Saroosh Ehsan ${ }^{2}$ \\ BDS, FCPS
}

OBJECTIVE: Supplementary local anesthetic techniques (Buccal Infiltration and Intraligamentary Injections) are used to achieve adequate pulpal anesthesia by supplementing the initial Inferior Alveolar Nerve Block (IANB). There was no study found in Pakistani literature which compared these two supplemental techniques with $2 \%$ Lidocaine. This study was conducted to compare the frequency of success of buccal infiltration verses intraligamentary local anesthetic techniques with $2 \%$ Lidocaine in patients with irreversible pulpitis.

METHODOLOGY: This randomized control trial was conducted in the Department of Operative Dentistry, at Fatima Memoial Hospital, Lahore from August 2017 to June 2018. A total of 82 patients presented with irreversible pulpitis in mandibular first molar were included in this study and divided in two groups of 41. Group A were administered Buccal Infiltration local anesthesia while Group B was administered Intraligamentary local anesthesia.

RESULTS: The results of the present study showed significant difference between success rate of Buccal Infiltration (34.1\%) and intraligamentary anesthetic technique $(65.9 \%)$ with $2 \%$ Lidocaine. $(\mathrm{p}$-value $=0.039)$.

CONCLUSION: This study concluded that Intraligamentary is a better supplementary technique to achieve adequate pulpal anesthesia as compared to buccal infiltration with $2 \%$ lidocaine in mandibular molar teeth with irreversible pulpitis. KEY WORDS: Endodontics. Irreversible pulpitis. Success. Inferior alveolar nerve block (IANB). Buccal infiltration (B.I). Intraligamentary injection (I.L).

HOW TO CITE: Naeem MH, Ehsan S. Comparison of success of buccal infiltration versus intraligamentary local anesthetic techniques in mandibular first molar with irreversible pulpitis. J Pak Dent Assoc 2019;28(4):166-170.

DOI: https://doi.org/10.25301/JPDA.284.166

Received: 10 July 2019, Accepted: 05 August 2019

\section{INTRODUCTION}

$\mathrm{P}$ atients that are suffering from symptomatic irreversible pulpitis have to undergo conventional root canal treatment. This condition is associated with central sensitization and peripheral sensitization which results in a reduction in threshold and an increase in responsiveness of the peripheral ends of nociceptors. ${ }^{1,2}$ This increased pain response results in difficulty in achieving the cessation of pain, especially when neurogenic inflammatory mediators have produced morphogentic modification in neurons, causing resistance of the nerve fibres to the anaesthetic. ${ }^{1,2,3}$ This condition poses a challenge for dental health care provider to achieve optimum analgesia during procedure. ${ }^{1}$

For conventional root canal treatment (RCT) in mandibular teeth, Inferior alveolar nerve block (IANB) is the conventional method for achieving effective localized

1. FCPS Resident, Department of Operative Dentistry, Fatima Memorial Hospital 2. Associate Professor, Department of Operative Dentistry, Fatima Memorial Hospital. Corresponding author: "Dr. Muhammad Haris Naeem"

<dr.harisqureshi@hotmail.com > analgesia. Unfortunately, this technique has poor success rate in irreversible pulpitis. Studies by Fowler et al and Kanna et al reported only $28 \%$ and $45.1 \%$ success rate after initial IANB using 2\% Lidocaine with 1:1,00,000 epinephrine respectively. ${ }^{4,5,6}$ Recognizing the importance of providing local anesthesia for patients undergoing dental procedures, clinicians use other methods to increase the effectiveness of anesthesia. ${ }^{4,5,8}$ They often administer local anesthesia (L.A) through supplementary techniques at different sites than primary IANB. These techniques target the nerve endings and nociceptors instead of blocking the inferior alveolar nerve trunk. ${ }^{4}$

The Buccal Infiltration (B.I) and Intraligamentary injections (I.L) are the most commonly used supplementary local anesthetic techniques due to their immediate onset and easier techniques. ${ }^{4,5}$ Recent literature reported that B.I with $4 \%$ articaine is significantly superior to other supplementary techniques $(\mathrm{P}=0.001)$. On the other hand, with $2 \%$ Lidocaine intraligamentary injections, a success rate of $50 \%$ was reported by Kanna et al and $56 \%$ by Nusstein, with using more precised computer controlled administration in 
irreversible pulpitis. ${ }^{4,5}$ This evidence shows that B.I with $4 \%$ articaine should be the first choice of supplementary local anesthetic technique in irreversible pulpitis. However, 4\% articaine is not available in Pakistan and 2\% Lidocaine is the most commonly used local anesthetic agent. ${ }^{5}$ Ashraf et al reported lower success rate of B.I with Lidocaine (29\%) as compared to Articaine (success rate of $71 \%$ ) with significant difference (P value $<0.001) .{ }^{9}$ There is no comparison found in local and international literature regarding the success of I.L versus B.I with $2 \%$ Lidocaine.

In light of this literature gap, it was found to be useful to know whether one should use B.I or I.L with $2 \%$ Lidocaine in irreversible pulpitis. This study had, therefore, been planned to compare B.I and I.L anesthetic techniques in a scientific way. The results of this study would add to the literature regarding better supplementary L.A technique in the management of primary IANB failure in mandibular 1st molar with irreversible pulpitis.

\section{METHODOLOGY}

This randomized control trial was conducted in the Department of Operative Dentistry, at Fatima Memoial Hospital, Lahore from August 2017 to June 2018. Sample size of 82 cases (irreversible pulpitis and failed initial IANB) was calculated with $80 \%$ power of test, $5 \%$ level of significance, P1 (for I.L) was 56\% and P2 (for B.I) was $29 \%$. A total of 142 patients of age range of 18-30 years presented with irreversible pulpitis were considered for this study. After administering initial IANB and confirming soft tissue anesthesia, pulpal anesthesia was evaluated using EPT. Heft Parker Visual Analogue Scale (HP-VAS) was used to grade the pain. It is a $170 \mathrm{~mm}$ long scale used to grade the pain response into a series of values that corresponds to no pain, mild, moderate and severe pain. An absent to mild pain $(\leq 54 \mathrm{~mm}$ in HP-VAS) to EPT upto the reading of 80 was considered as successful pulpal anesthesia. In case of ineffective pulpal anesthesia, patients were included in the study and randomly allocated into one of the two groups through lottery method. The supplemental L.A (B.I in group A and I.L in group B) was administered by the researcher without informing the patients. After five minutes, pulpal anesthesia was again checked with EPT and pain response was graded using HP-VAS. An absent or mild pain $(\leq 54$ $\mathrm{mm}$ in HP-VAS) to EPT upto the reading of 80 was considered as successful pulpal anesthesia. All the data was recorded in a specially designed proforma. The outcome variable i.e. success rate for each of the anesthetic technique was calculated as percentage of successful anesthesia.

The data was entered and analyzed in the SPSS-20. For descriptive analysis, mean and standard deviation was reported for age. Percentage for male and female participants was presented for gender distribution. The success rate for I.L and B.I was determined by calculating the percentages of successful anesthesia. A chi-square test was used to determine the significance of the difference between the success of these two supplemental techniques. A P value of 0.05 or less was taken as significant. Data was stratified for age, gender and pain score to address the effect modifiers. Post stratification chi-square was applied with $p$ value $<0.05$ considered as significant.

\section{RESULTS}

This single blinded randomized control trial was conducted on 142 patients with irreversible pulpitis in mandibular $1^{\text {st }}$ molar. These included 77 female patients and 65 males with age range from 18-30. There were 46 (32.4\%) participants in age range 18-22, $63(44.4 \%)$ in age range 23-26 and $33(23.4 \%)$ in age range $27-30$ years. Mean age of the patients was 24 years and 9 months with S.D 3.556.

These patients were administered IANB with $2 \%$ Lidocaine with 1:100,000 epinephrine. Table 1 shows the pain response to EPT after administration IANB. Frequency

Table 1: Frequency of Pain Responses To EPT After Initial IANB

\begin{tabular}{|c|c|c|c|}
\hline $\begin{array}{c}\text { Pain } \\
\text { Responses }\end{array}$ & Frequency & Percentage & $\begin{array}{c}\text { Anesthetic } \\
\text { Success }\end{array}$ \\
\hline Absent & 34 & 23.9 & YES \\
\hline Mild pain & 26 & 18.3 & $\begin{array}{c}n=60 \\
42.25 \%\end{array}$ \\
\hline Moderate & 54 & 38.0 & $\begin{array}{c}\text { NO } \\
\mathbf{n}=\mathbf{8 2}\end{array}$ \\
\hline Severe & 28 & 19.75 & $57.75 \%$ \\
\hline
\end{tabular}

of absent and mild pain shows the anesthetic success of pulpal anesthesia after IANB. The frequency of successful anesthesia was $42.2 \%$ (60 patients out of total 142) with a failure rate of $57.8 \%(82 / 142)$. These 82 patients were considered eligible to be included in this study. When success of IANB was compared among male and female genders, no statistically significant difference was found ( $\mathrm{p}=0.101) .33$ female patients $(42.85 \%)$ and 27 male patients $(40.53 \%)$ achieved successful pulpal anesthesia after primary IANB.

82 patients who failed to achieve pulpal anesthesia, were included in this study and randomly divided into two groups of 41 each, to receive either Buccal Infiltration (Group A) 
Table 2: Age Distribution in Supplemental L.A Groups

\begin{tabular}{|c|c|c|c|c|}
\hline Supplemental L.A Groups & $18-22$ & $23-26$ & $27-30$ & Total \\
\hline $\begin{array}{c}\text { Buccal Infiltration } \\
\text { Injection } \\
\text { (Group A) }\end{array}$ & 13 & 21 & 7 & 41 \\
\cline { 2 - 5 } & $31.7 \%$ & $51.2 \%$ & $17.1 \%$ & \\
\hline $\begin{array}{c}\text { Intraligamentary } \\
\text { Injection } \\
\text { (Group B) }\end{array}$ & 15 & 17 & 9 & \\
\hline Total & 28 & $41.5 \%$ & $22.9 \%$ & 41 \\
\hline
\end{tabular}

or Intraligamentary injection (Group B). Both groups had 22 female patients and 19 male patients. Table 2 shows the age distribution of patients in Group A and B. There was no significant difference among two groups on the basis of age distribution $(\mathrm{P}=0.666)$

When pulpal anesthetic success rate by B.I and I.L were compared, I.L injection performed significantly better (success rate is $65.9 \%$ ) than B.I (success rate is $34.1 \%$ ) (Table 3 ). There was a statistically significant difference found between these two techniques $(\mathrm{P}=0.039)$. When the frequency of success of IL and BI were compared among males and females (Table 4), females have better success rate for BI $(45.5 \%)$ than males $(21.1 \%)$ with

Table 3: Comparison of Frequency of Successful Anesthesia among Two Groups

\begin{tabular}{|c|c|c|c|c|}
\hline \multirow{2}{*}{ Groups } & \multicolumn{2}{|c|}{ Success } & \multirow{2}{*}{ Total } & \multirow{2}{*}{ P- Value } \\
\cline { 2 - 3 } & Yes & No & & \\
\hline $\begin{array}{c}\text { Buccal } \\
\text { infiltration }\end{array}$ & 14 & 27 & 41 & 0.039 \\
\hline Intraligamentary & $\mathbf{( 3 4 . 1 \% )}$ & $(65.9 \%)$ & & \\
\hline Total & 41 & 14 & 41 & \\
\hline
\end{tabular}

Table 4: Frequency of Successful Supplemental Techniques in Males and Females

\begin{tabular}{|c|c|c|c|c|}
\hline \multirow[t]{2}{*}{ Gender } & \multirow{2}{*}{$\begin{array}{l}\text { Anesthetic } \\
\text { Technique }\end{array}$} & \multicolumn{2}{|c|}{ Pain Response } & \multirow[t]{2}{*}{ P-Value } \\
\hline & & Successful & Failed & \\
\hline \multirow{2}{*}{$\begin{array}{l}\text { Female } \\
(n=22)\end{array}$} & Buccal Infiltration & $10(45.5) \%)$ & $12(54.6 \%)$ & \multirow[t]{2}{*}{0.748} \\
\hline & Intraligamentary & $13(59.1 \%)$ & $9(40.9 \%)$ & \\
\hline \multirow{2}{*}{$\begin{array}{c}\text { Male } \\
(n=19)\end{array}$} & $\begin{array}{l}\text { Buccal Infiltration } \\
\text { (22) }\end{array}$ & $4(21.1 \%)$ & $15(78.9 \%)$ & \multirow[t]{2}{*}{0.009} \\
\hline & $\begin{array}{c}\text { Intraligamentary } \\
\text { (19) }\end{array}$ & $14(73.6 \%)$ & $5(26.4 \%)$ & \\
\hline
\end{tabular}

statistically significant difference $(\mathrm{p}<0.05)$. Males performed better with I.L technique with a success rate of $73.6 \%$ as compared to $59.1 \%$ in buccal infiltration ( $\mathrm{p}>0.05)$.

When these two techniques were compared among different age groups, in younger age group (18-22 years), both IL and BI have similar success rate $(53.3 \%$ and $53.8 \%$ respectively) with no significant difference $(\mathrm{p}=0.820)$. 23-26 years old patients reported decreased success rate of BI $(23.8 \%)$ and increased success rate with IL (76.5\%) with significant difference $(\mathrm{p}=0.008)$. Similar results were found in 27-30 years old patients, with success rate of BI $(28.6 \%)$ is less than IL $(66.7 \%)$ with no significant difference $(p=0.266)$.

\section{DISCUSSION}

This present study aimed at determining the better anesthetic technique out of buccal infiltration and intraligamentary injections, with $2 \%$ Lidocaine with $1: 100,000$ epinephrine, in terms of success rate. Both these techniques were administered in patients who failed to achieve adequate pulpal anesthesia with conventional IANB in mandibular 1st molar with irreversible pulpitis.

IANB was administered to achieve adequate pulpal anesthesia which was confirmed by EPT (An absent response to mild pain upto the reading of 80 was considered as successful anesthesia). IANB was assessed to be successful in 60 patients (success rate: $42.3 \%$ ). 82 patients $(57.7 \%$ ) failed to achieve adequate pulpal anesthesia with conventional IANB. These results are similar to Kanna et al who reported success rate of $45.1 \%$ in 182 subjects. ${ }^{5}$ Similarly, Toratamano ${ }^{10}$ also reported $45 \%$ success rate of IANB with $2 \%$ Lidocaine which is less than that achieved with $4 \%$ articaine $(65 \%)$. Claffey et $\mathrm{al}^{11}$ reported a lower success rate of IANB in 70 subjects with $2 \%$ lidocaine $(23 \%)$, as well as $4 \%$ articaine (24\%). Similar to Claffey, Simpson et al $^{12}$ reported $24 \%$ success rate of IANB with $3.6 \mathrm{~mL}$ of $2 \%$ lidocaine with 1:100,000 epinephrine in mandibular molars that were not pretreated with anti-inflammatory medicines. Success rate was increased to $32 \%$ after the administration of antiinflammatory drug. Oleson et al confirmed better success rate of IANB with preoperatively administered ibuprofen (41\%) than placebo (35\%). ${ }^{13}$ The difference between these success rates with the current study is may be due to difference in individual diagnosis as well as racial differences.

When success rates of these two techniques were compared, intraligamentary injection (65.9\%) was significantly better than buccal infiltration (34.1\%). When this success rate was compared among female and male patients, buccal infiltration was more successful in females $(45.5 \%)$ than in males $(21.1 \%)$ with statistically significant difference $(\mathrm{p}<0.05)$. On the other hand, intraligamentary injection performed well with both males (73.6\%) and females (59.1\%) with insignificant difference. The results of this study were comparable to the study conducted by Walton and Abbot. ${ }^{14}$ These authors conducted their study in 120 patients and reported success rate of $92 \%$ 
after primary and repeat intraligamentary injections. Smith et al noted the similar success rate $(93 \%) .{ }^{15} \mathrm{Lin}$ et al conducted a study on 151 patients with irreversible pulpitis to evaluate the anesthetic efficacy of IL. IL anaesthesia was found to be successful in $92.1 \%$ of the teeth. ${ }^{16}$ The success rates reported by these studies were better than the current study (73.6\%). This may be due to the fact that these past studies were conducted in asymptomatic irreversible pulpitis, contrary with the current study which included only symptomatic irreversible pulpitis patients.

Nusstein et al reported a lower success rate $(56 \%)$ in mandibular teeth with irreversible pulpitis when $2 \%$ lidocaine with 1:100,000 epinephrine was administered as an intraligamentary injection by computerized delivery system. ${ }^{18}$ Similar study was conducted by Bonar et al to compare the anesthetic efficacy of I.L with 2\% Lidocaine and $4 \%$ articaine using computer controlled administration. ${ }^{17}$ These authors reported lower success rates with both articaine (32\%) and lidocaine $(30 \%) .{ }^{17}$ These success rates are less than the current study, which may be due to the difference in individuals' diagnosis as well as in the volume of anesthetic solution used. Also the use of computer-controlled administration may be responsible for this low success rates, and more clinical studies are required to probe it. The use of buccal infiltration technique with $4 \%$ articaine as a supplementary local anesthesia has been reported in several studies to be an effective method to achieve adequate pulpal anesthesia. Kanna et al compared IL, Intraosseous injection with $2 \%$ Lidocaine and B.I with $4 \%$ articaine to determine the better supplementary anesthetic technique. He reported that B.I with $4 \%$ articaine is the most effective supplementary technique with a success rate of $84 \% .{ }^{5}$ Ashraf et al also reported similar success rate of BI with $4 \%$ articaine (71\%), which is significantly different from that of $2 \%$ Lidocaine (29\%). ${ }^{9}$ Aggarwal et al reported $47 \%$ success rate of B.I with $2 \%$ lidocaine, which is less than that of $4 \%$ articaine (67\%) in mandibular molars with irreversible pulpitis. ${ }^{19}$ The better performance of $4 \%$ articaine can be attributed to its increased lipophilicity. Although, it is an effective method of achieving anesthesia, it can't be used in our setting because of the unavailability of $4 \%$ articaine in Pakistan. With 2\% Lidocaine, BI is not as effective as with articaine as reported by Ashraf, Aggarwal. These success rates of $29 \%$ and $47 \%$ are comparable to the current study (34.1\%).

An important observation is made in this study that BI was more successful in females $(45.5 \%)$ than in males $(21.1 \%)$ with a statistically significant difference $(\mathrm{p}<0.05)$. This may be due to the thinner cortical plates and less dense bone quality that make the diffusion of local anesthetic solution easier in females.
To the best of our knowledge, comparison of Buccal Infiltration and intraligamentary injection with $2 \%$ Lidocaine in mandibular teeth with irreversible pulpitis was done in this study for the first time in Pakistan. It would be beneficial to conduct similar studies on teeth with irreversible pulpitis. Our higher chance of success rate of intraligamentary injection than buccal infiltration with $2 \%$ lidocaine, according to our logistic regression analysis, would provide dentists and patients with better anesthesia choices if future studies confirm such findings.

\section{CONCLUSION}

This study concluded that intraligamentary injection is better supplementary local anesthetic technique than buccal infiltration in mandibular 1st molar with irreversible pulpitis.

\section{CONFLICT OF INTEREST}

Authors hereby declare no conflict of interest in this study.

\section{REFERENCES}

1. Hargreaves KM, Keiser K. Local anesthetic failure in endodontics: mechanisms and management. Endod Topics. 2002;1:26-9. https://doi.org/10.1034/j.1601-1546.2002.10103.x

2. Hargreaves KM, Berman LH. Cohen's pathways of the pulp. Elsevier Health Sciences; 2015.

3. Potocnik I, Bajrovic F. Failure of inferior alveolar nerve block in endodontics. Dent Traumatol.-1999;15:247-51.

https://doi.org/10.1111/j.1600-9657.1999.tb00782.x

4. Parirokh M, Sadr S, Nakhaee N, Abbott PV, Askarifard S. Efficacy of supplementary buccal infiltrations and intraligamentary injections to inferior alveolar nerve blocks in mandibular first molars with asymptomatic irreversible pulpitis: a randomized controlled trial. Int Endod J. 2014;47:926-33.

https://doi.org/10.1111/iej.12236

5. Kanaa MD, Whitworth JM, Meechan JG. A prospective randomized trial of different supplementary local anesthetic techniques after failure of inferior alveolar nerve block in patients with irreversible pulpitis in mandibular teeth. J Endod. 2012;38:421-25.

https://doi.org/10.1016/j.joen.2011.12.006

6. Fowler S, Drum M, Reader A, Beck M. Anesthetic Success of an Inferior Alveolar Nerve Block and Supplemental Articaine Buccal Infiltration for Molars and Premolars in Patients with Symptomatic Irreversible Pulpitis. Journal of endodontics. 2016;42:390-92. https://doi.org/10.1016/j.joen.2015.12.025

7. Shumaila S, Memon AB, Shaikh MI, Afridi AK, Dahri WM, Malhi 
P. Evaluation of pain after administration of local anesthesia with and without medication (midazolam) in irreversible pulpitis in a sample of Sindh. Pak Oral Dent J. 2014;34.

8. Rajput F, Katpar S, Shaikh MI, Khatoon S. Evaluation of anesthetic efficacy of $4 \%$ articaine as buccal infiltration vs $2 \%$ lidocaine as IANB in the mandibular 1st molar with irreversible pulpitis. Pak Oral Dent J. $2015 ; 35$.

9. Ashraf H, Kazem M, Dianat O, Noghrehkar F. Efficacy of articaine versus lidocaine in block and infiltration anesthesia administered in teeth with irreversible pulpitis: a prospective, randomized, doubleblind study. J Endod. 2013;39:6-10. https://doi.org/10.1016/j.joen.2012.10.012

10. Tortamano IP, Siviero M, Costa CG, Buscariolo IA, Armonia PL. A comparison of the anesthetic efficacy of articaine and lidocaine in patients with irreversible pulpitis. J Endod. 2009;35:165-68 https://doi.org/10.1016/j.joen.2008.10.020

11. Claffey E, Reader A, Nusstein J, Beck M, Weaver J. Anesthetic efficacy of articaine for inferior alveolar nerve blocks in patients with irreversible pulpitis. J Endod. 2004;30:568-71

https://doi.org/10.1097/01.DON.0000125317.21892.8F

12. Simpson M, Drum M, Nusstein J, Reader A, Beck M. Effect of combination of preoperative ibuprofen/acetaminophen on the success of the inferior alveolar nerve block in patients with symptomatic irreversible pulpitis. J Endod 2011;37:593-97.

https://doi.org/10.1016/j.joen.2011.02.015

13. Oleson M, Drum M, Reader A, Nusstein M, Beck M. Effect of preoperative ibuprofen on the success of the inferior alveolar nerve block in patients with irreversible pulpitis. J Endod 2010;36:379-82. https://doi.org/10.1016/j.joen.2009.12.030
14. Walton RE, Abbott BJ. Periodontal ligament injection: a clinical evaluation. The J Am Dent Assoc. 1981;103:571-5.

https://doi.org/10.14219/jada.archive.1981.0307

15. Smith GN, Walton RE, Abbott BJ. Clinical evaluation of periodontal ligament anesthesia using a pressure syringe. J Am Dent Assoc 1983;107:953-56.

https://doi.org/10.14219/jada.archive.1983.0357

16. Lin S, Wigler R, Huber R, Kaufman AY. Anaesthetic efficacy of intraligamentary injection techniques on mandibular molars diagnosed with asymptomatic irreversible pulpitis: A retrospective study. Aust Endod J. 2017;43:34-7. https://doi.org/10.1111/aej.12169

17. Bonar T, Nusstein J, Reader A, Drum M, Fowler S, Beck M. Anesthetic Efficacy of Articaine and Lidocaine in a Primary Intraseptal Injection: A Prospective, Randomized Double-Blind Study. Anesthesia progr. 2017;64:203-11.

https://doi.org/10.2344/anpr-64-04-10

18. Nusstein J, Claffey E, Reader A, Beck M, Weaver J. Anesthetic effectiveness of the supplemental intraligamentary injection, administered with a computer-controlled local anesthetic delivery system, in patients with irreversible pulpitis. J Endod. 2005;31:35458.

https://doi.org/10.1097/01.DON.0000140565.88940.60

19. Aggarwal V, Jain A, Kabi D. Anesthetic efficacy of supplemental buccal and lingual infiltrations of articaine and lidocaine after an inferior alveolar nerve block in patients with irreversible pulpitis. J Endod 2009;35:925-29.

https://doi.org/10.1016/j.joen.2009.04.012 